\title{
INTEGRACIÓN JURÍDICA DE LOS INMIGRANTES INDÍGENAS. PROPUESTA TEÓRICA CONCEPTUAL ${ }^{1}$
}

LEGAL INTEGRATION OF INDIGENOUS IMMIGRANTS. CONCEPTUAL THEORETICAL PROPOSAL

SAÚL RAMÍREZ SÁNCHEZ²

RESUMEN: La integración de los inmigrantes a la sociedad estadounidense ha sido abordada desde diversos ámbitos (social, cultural, político y económico) y a la luz de las perspectivas de la asimilación o el multiculturalismo, concibiendo el proceso de incorporación como unidireccional, donde los recién llegados tienen la responsabilidad de incorporarse a la sociedad receptora adaptándose a la cultura dominante. Por el contrario, la integración jurídica debe entenderse como un proceso bidireccional en donde el Estado implementa políticas para que los inmigrantes se incorporen a la sociedad, así como los recién llegados hagan lo propio para formar parte de la vida del lugar de establecimiento. En el fondo de esta noción está el que los inmigrantes indígenas tengan derecho a tener derechos. Para ello, se propone un modelo de análisis sobre los niveles de incorporación de estos sujetos, a través de dos unidades: la cultura jurídica y el acceso a la justicia como política jurídica.

Palabras Clave: Integración furídica, Inmigrantes, Indigenas, Cultura furídica, Acceso a la Fusticia, Política Jurídica, Sociología del Derecho.

Abstract: The integration of immigrants into American society has been approached from various areas (social, cultural, political and economic) and in light of the perspectives of assimilation or multiculturalism, conceiving the process of incorporation as unidirectional, where

${ }^{1} \mathrm{El}$ presente documento forma parte del primer capítulo de la tesis de investigación para obtener el grado de Doctor en Derecho.

${ }^{2}$ Estudiante del Programa de Doctorado en Derecho de la Estación Noroeste de Investigación y Docencia del Instituto de Investigaciones Jurídicas, UNAM; y miembro fundador de la organización Agenda Ciudadana por el Desarrollo y la Corresponsabilidad Social A.C. <saulrasa13@gmail.com> 
newcomers have the responsibility of joining the host society adapting to the dominant culture. On the contrary, legal integration should be understood as a bidirectional process in which the State implements policies for immigrants to join society, just as newcomers do the same to be part of the life of the place of establishment. At the bottom of this notion is that indigenous immigrants have the right to have rights. To do this, a model of analysis is proposed on the levels of incorporation of these subjects, through two units: legal culture and access to justice as a legal policy.

KeyYords: Legal Integration, Immigrants, Indigenous, Legal Culture, Access to Fustice, Legal Policy, Sociology of Law.

SUMARIO: I. Introducción, II. La integración de los inmigrantes en sus diversos ámbitos, III. Integración económica, IV. Integración social, V. Integración cultural, VI. Integración política, VII. La integración jurídica. Una propuesta, VIII. La cultura jurídica como parte de la integración jurídica, IX. Acceso a la justicia como política jurídica, X. Modelo de integración jurídica, XI. Consideraciones finales, XII. Fuentes.

\section{I N T RO D U CCIÓ N}

$\int\left\{\begin{array}{l}\text { a migración puede analizarse en tres grandes dimensiones: 1) } \\ \text { los que investigan el inicio del movimiento migratorio o las } \\ \text { causas de los desplazamientos de personas de un lugar a otro; }\end{array}\right.$ 2) la dimensión que analiza la perdurabilidad del movimiento migratorio o mantenimiento de dicha movilidad y; 3) los que se refieren a la comprensión de las consecuencias y efectos de los movimientos migratorios tanto en el lugar de origen como de llegada. En esta dimensión se encuentra el objeto del presente estudio: la “integración”. Este es un concepto fundamental para los estudios de la migración y la teoría social, sobre todo, cuando en las investigaciones se tiene como propósito describir cómo los recién llegados encuentran vida en el nuevo país y 
se incorporan al orden social, comprendiendo y explicando el tipo de sociedad en la que se encuentra. Esta siempre ha sido una preocupación constante para los países que reciben migrantes, preocupación que tiene que ver con la idea de la cohesión social, es decir, con el tipo ideal de sociedad que se quiera construir con la llegada de los inmigrantes, una sociedad donde se restringen los derechos de las personas inmigrantes o bien, se les garantice.

Las investigaciones han analizado la problemática de incorporación de los inmigrantes al lugar de llegada en el ámbito cultural, social, económico y político, dejando de lado el aspecto jurídico, el cual se concentra en la construcción de tipo ideal de unidad y orden que se desea para la sociedad y el tipo de modelo que se plantea para abordar dicha problemática en la comunidad receptora. Problemática que se puede resumir en dos grandes dimensiones: la primera se refiere a la protección de los valores nacionales del país de llegada y la cohesión social de los individuos en la sociedad de establecimiento, es decir, en la búsqueda del orden social para prevenir el conflicto; mientras que en la segunda dimensión busca encarar la diversidad cultural y étnica frente al tema de seguridad nacional; misma que ha descuidado los asuntos sobre el reconocimiento de derechos de los inmigrantes, la discriminación y la exclusión.

Bajo esta problemática se propone abordar el tema de la integración de los inmigrantes indígenas ${ }^{3}$ mexicanos en San Diego, California, a la

${ }^{3}$ En los estudios de la migración indígena se tiene la errónea percepción de que los pueblos indígenas son estáticos, enraizados a su territorio y a su cultura. Cfr. Carlos Yescas Angeles Trujano, A Framework for Understanding Indigenous Migration, OIM, Organización Internacional para las Migraciones, 2008, p. 7. Por el contrario, la movilización de los pueblos indígenas es dinámica y moderna, su migración es un fenómeno multiétnico y es más antiguo que la migración mestiza. Además, se ha caracterizado por tener una movilidad transnacional debido a que guarda fuertes vínculos con sus 
luz del ámbito jurídico, a fin de comprender en qué medida la cultura jurídica y el acceso a la justicia como política jurídica explican los niveles de integración de estos inmigrantes a la sociedad estadounidense, bajo la premisa que todo inmigrante como persona tiene el derecho a tener derechos, independientemente de su situación migratoria. Para ello, se propone una definición de integración jurídica, la cual estará acompañada de un modelo de análisis que coadyuve a explicar los grados de incorporación de los recién llegados en la sociedad estadounidense. Este modelo será construido por dos unidades de análisis: la cultura jurídica y el acceso a la justicia como política jurídica; pues suponemos que a mayor conocimiento del derecho estadounidense y a mayor implementación de políticas jurídicas de acceso a la justicia para los inmigrantes, será mayor el éxito de su integración a la sociedad estadounidense. La

comunidades de origen. Cfr. Laura Velasco Ortiz y Dolores París Pombo, "Indigenous Migration in Mexico and Central America: Interethnic Relations and Identity Transformations" in Latin American Perspectives, 2014, Vol.41, Num. 3, pp. 5-25. De hecho, la pertinencia de estudiar la migración de los pueblos indígenas corresponde a que existen planteamientos y problemáticas que la diferencian de otras movilizaciones, diferencias que van desde la perspectiva de derechos humanos y la demanda del reconocimiento como sujetos de derechos, hasta la participación activa para incidir en las decisiones que los afectan y evitar la fuerte discriminación de la que son objeto, transitando por tres culturas jurídicas (estadounidense, mexicana e indígena). Esta situación reconfigura la cultura jurídica de los inmigrantes indígenas y, por supuesto, es un ejemplo claro de la integración jurídica. Es por ello que esta defensa a los derechos humanos es un reflejo de las actividades de las asociaciones y comunidades transnacionales de migrantes indígenas en Estados Unidos, las cuales han desarrollado una gran experiencia en acciones colectivas para el desarrollo comunitario, justicia social y democratización política. Acciones colectivas que han surgido de los procesos que han experimentado los indígenas migrantes por la discriminación y exclusión racial vividas en Estados Unidos, lo que ha llevado a la conformación de una sociedad civil indígena organizada y unida que les ha permitido sortear sus adversidades y exigir políticas especificas para acceder a la justicia. Cfr. Jonathan Fox, y Gaspar Rivera-Salgado, (Coords.), Indígenas mexicanos migrantes en los Estados Unidos, México, H. Cámara de Diputados, LIX Legislatura, Universidad de California, Santa Cruz, Universidad Autónoma de Zacatecas, Miguel Ángel Porrúa, 2004. 
estructura del documento se compone por tres apartados: 1) el debate de la integración en sus diversos ámbitos; 2) la propuesta de concepción de integración jurídica y; 3) el modelo sobre los niveles de integración jurídica de los inmigrantes indígenas mexicanos en la sociedad estadounidense, construido por las unidades de la cultura jurídica y del acceso a la justicia como política jurídica.

\section{LA INTEGRACIÓN DE LOS INMIGRANTES EN SUS DI-}

\section{VERSOS ÁMBITOS}

El proceso de integración se ha abordado desde las diversas perspectivas teóricas de la asimilación y el multiculturalismo ${ }^{4}$, mismas que tienen como eje predominante la cultura, como su factor más relevante para comprender la incorporación de los inmigrantes a la sociedad dominante, el cual es concebido como un proceso "uni-direccional". Si bien es cierto que los estudios que se realizaron durante el siglo XX sobre inmigrantes que llegaron a Estados Unidos fueron comprendidos por la

\footnotetext{
${ }^{4}$ Cfr. Jeffrey C. Alexander, "Theorizing the 'modes of incorporation': Assimilation, hyphenation, and multiculturalism as varieties of civil participation", in Sociological Theory, 2001, Vol. 19, № 3, pp. 237-249; Will Kymlicka, Ciudadania multicultural. Una teoría liberal de los derechos de las minorías, España, Paidós, 1996; La política vernácula. Nacionalismo, multiculturalismo y ciudadanía, España, Paidós, 2003; Douglas Hartmann y Joseph Gerteis, "Dealing with Diversity: Mapping Multiculturalism in Sociological Terms", in Sociological Theory, 2005, Vol. 23, № 2, pp. 218-240; Christian Joppke, "The retreat of multiculturalism in the liberal state: theory and policy", in The British fournal of $S_{0-}$ ciology, 2004, Vol. 55, № 2, pp. 237-257; Steven Vertovec, "Towards post multiculturalism? Changing communities, conditions and contexts of diversity", in International Social Science fournal, 2010, Vol. 61, № 199, pp. 83-95; Adrian Favell, "Europe’s identity problem", in West European Politics, 2005, Vol. 28, № 5, pp. 1109-1116; Nathan Glazer, "We are all multiculturalists now", in Multiculturalism in the United States: Current issues, contemporary voices, Pine Forge Press, 2000, pp. 445-454; Alan Wolfe, "Bening Multiculturalism", in Multiculturalism in the United States: Current issues, contemporary voices, Pine Forge Press, 2000, pp. 455-464.
} 
perspectiva hegemónica de la asimilación ${ }^{5}$, también es cierto que estas investigaciones fueron desacreditadas en la década de los setentas por el llamado resurgimiento étnico ${ }^{6}$, donde la asimilación fue entendida como una ideología coercitiva de americanización forzosa, buscando eliminar cualquier diferencia étnica entre los inmigrantes.

En Europa, después de la $2^{\mathrm{a}}$ Guerra Mundial, los académicos prefirieron abordar el enfoque de la integración en lugar de las perspectivas de la asimilación ${ }^{7}$, ya que desde el punto de vista político y moral, es

\footnotetext{
${ }^{5}$ Para comprender los orígenes de la Asimilación y su hegemonía. Cfr. Robert Park,
} "Human migration and the marginal man", in American fournal of Sociology, 1928, Vol. 33, № 6, pp. 881-893; "Racial assimilation in secondary groups with particular reference to the Negro", in American fournal of Sociology, 2014, Vol. 19, № 5, pp. 606-623; Peter Kivisto, "Robert E. Park's Theory of Assimilation and Beyond", in The Anthem Companion to Robert Park, Anthem Press, 2017, pp. 131-158; William Thomas y Florian Znaniecki, The Polish peasant in Europe and America: A classic work in immigration history, Chicago, University of Illinois Press, 1996; Arthur Schlesinger Meier, "The significance of immigration in american history", in The American fournal of Sociology, 1924, Vol. 27, № 1 , pp. 71-78.

${ }^{6}$ Este resurgimiento étnico tuvo varias influencias y una de ellas fue el resolutivo del Tribunal Supremo de Estados Unidos sobre el caso Brown vs. Board of Education en 1969, donde se abolía el sistema de instalaciones segregadas para niños negros y blancos en el Sur, lo que significo una serie de criterios para la salvaguarda de la igualdad racial. Cfr. Will Kymlicka, Ciudadania multicultural... cit. p. 89; John C. Walter, "The Influence of African American History on U.S. History Survey Textbooks since the 1970s”, in Butler, Johnnella E. (Ed.), Color-Line to Borderlands. The Matrix of American Ethnic Studies, Washington, The University of Washington Press, 2001, pp. 65-100.

${ }^{7}$ Tales como la Teoría Clásica de la Asimilación, la Nueva Teoría de la Asimilación o la Asimilación Segmentada. Cfr. Milton M. Gordon, “Assimilation in America: Theory and Reality”, in Daedalus, 1961, Vol. 90, № 2, pp. 263-285; Assimilation in American Life: The Role of Race, Religion, and National Origins, New York, Oxford University Press, 1964; Richard D. Alba, Ethnic identity: The transformation of white America, Yale University Press, 1990; "Bright vs. blurred boundaries: Second generation assimilation and exclusion in France, Germany, and the United States”, Ethnic and Racial Studies, 2005, Vol. 28 № 1, pp. 20-49; Richard D. Alba y Victor Nee, "Rethinking assimilation theory for a new era of immigration”, en The International Migration Review, 1997, Vol. 31, №4, pp. 827874; Remaking the American Mainstream: Assimilation and the New Immigration, Cambridge, Harvard University Press, 2005; John R. Logan et al., "Immigrant enclaves and ethnic communities in New York and Los Angeles”, in American Sociological Review, 2002, Vol. 
un término ideológico más neutral, menos coercitivo y discriminatorio, sobre todo, porque permite entender con más amplitud y profundidad como los inmigrantes hacen su vida en la sociedad receptora ${ }^{8}$. La diferencia entre estos términos pareciera ser una cuestión semántica, sin embargo, el análisis de las “inter-relaciones” humanas en la sociedades receptoras han sido estudiadas por la sociología de las migraciones desde diversos puntos de vista y con una amplia gama de perspectivas ${ }^{9}$. El eje en común de estas perspectivas es el análisis de los migrantes que cruzan las fronteras y se llegan a establecer en las sociedades, donde los Estados buscan incorporar o restringir los derechos de los recién llegados. Además de controlar la movilidad y acceso de las personas ${ }^{10}$, definiendo la soberanía y estipulando los diversos procesos para adquirir derechos, además de muchos otros factores que interactúan entre sí y que permiten comprender el origen, mantenimiento y los efectos de la migración.

En este contexto, la integración se concibe, siguiendo a Alarcón, Escala y Odgers, como un proceso "bi-direccional" donde, por un lado, la sociedad se integra a los inmigrantes y, por el otro lado, los recién llegados se integran a la sociedad. Estos investigadores explican la integración de los inmigrantes

67, № 2, pp. 299-322; Min Zhou, "Segmented Assimilation: Issues, Controversies, and Recent Research on the New Second Generation”, en The International Migration Review, 1997, Vol. 31, № 4, pp. 975-1008; Peter Kivisto y Thomas Faist, Beyond a Border: The Causes and Consequences of Contemporary Immigration, Los Angeles, Pine Forge Press, 2010; Alejandro Portes y Min Zhou, "The New Second Generation: Segmented Assimilation and Its Variants", in Annals of the American Academy of Political and Social Science, 1993, Vol. 530, № 1 , pp. 74-96.

${ }^{8}$ Cfr. David Fitzgerald, "The Sociology of International Migration”, in Caroline B. Brettel y James J. Hollifield (Eds.), Migration Theory: Talking across discipline, New York, Routledge, 2015, pp. 115-147.

${ }^{9}$ Hay diversas posturas para comprender la dinámica de los inmigrantes en los lugares de establecimiento, Fitzgerald distingue cinco perspectivas: Selectividad; Asimilación Clásica; Asimilación Segmentada; Transnacionalismo y; Dissimilación.

${ }^{10}$ Cfr. J. Nevins, Operation Gatekeeper: The rise of the "illegal alien" and the remakin of the US-Mexico boundary, London, Routledge, 2001. 
a través de un proceso de doble vía que se sustenta en la formación de estrategias y de modalidades diferenciadas que han sido "desarrolladas por los inmigrantes mismos y por los Estados tanto de origen como de destino"11, recuperando la dialéctica de ambos procesos. Este concepto de integración como proceso "bi-direccional" será utilizado en el ámbito de lo jurídico y, que dicho sea de paso, es una postura que se ubica en los terrenos de la sociología del derecho, la cual es una nueva forma de interpretar y comprender el proceso de integración de los inmigrantes en el Estado receptor. Bajo este contexto, se brindará una pincelada de la integración de los inmigrantes desde sus diversos ámbitos tales como el económico, político, social y cultural, para dejar en último lugar el tema de la integración jurídica.

\section{IN TEGRACIÓN ECONÓMICA}

En las últimas décadas se han producido estudios especializados sobre los diversos niveles y modos de incorporación de los inmigrantes en la sociedad receptora. De hecho, "las migraciones han dado lugar a una inmensa pluralidad de temas, uno de los que han dominado incluso hasta la actualidad la agenda de investigación es el referido a las maneras en que los inmigrantes se integran en la sociedad de destino" ${ }^{12}$, los cuales han sido analizados por distintos ángulos que van desde la integración económica, la cultural, la social hasta la política.

${ }^{11}$ Cfr. Rafael Alarcón, Luis Escala Rabadány Olga Odgers Ortiz, Mudando el hogar al norte. Trayectorias de integración de los inmigrantes mexicanos en Los Ángeles, Tijuana, El Colegio de la Frontera Norte, 2012, pp. 48.

${ }^{12}$ Luciana Gandini, ¿ Escapando de la crisis? Un estudio comparativo de trayectorias laborales de migrantes argentinos en la Ciudad de México y Madrid, México, Universidad Nacional Autónoma de México, 2015, p. 35. 
En el caso de la integración económica de los inmigrantes en el lugar de establecimiento se aborda la problemática que enfrentan "los migrantes de países del sur [...] para el logro de la integración socioeconómica en las economías industrializadas" ${ }^{13}$. La llegada de inmigrantes a las economías industrializadas es un tópico que ha sido analizado por diversos investigadores, a fin de comprender el proceso de integración económica desde diversas ópticas que versan sobre los inmigrantes y su inserción laboral, la igualdad de los salarios en los centros de trabajo, el auto empleo, el surgimiento de economías étnicas, de inversiones en bienes inmuebles, entre muchos otras variables ${ }^{14}$.

Estas ópticas de estudio esbozan de manera muy ilustrativa las propuestas teóricas más abordadas en las investigaciones sobre la integración económica, mismas que van desde el abordaje de la perspectiva del homo economicus (en donde los inmigrantes evolucionan de individuos a grupos con vínculos fuertes en el mercado laboral), pasando por la propuesta teórica neoclásica del desplazamiento, la perspectiva del mercado de trabajo segmentado, la teoría de la sucesión laboral, la perspectiva de la integración laboral de los inmigrantes, hasta la propuesta del enfoque de la integración económica, la cual se llega a interpretar a través de tres variables de análisis: 1) inserción en el mercado de trabajo; 2) formación de negocios en Estados Unidos y México; y 3) la propiedad de bienes inmuebles en los dos países ${ }^{15}$.

\footnotetext{
${ }^{13}$ Luciana Gandini, ¿ Escapando de la crisis?... cit. p. 35.

14 Rafael Alarcón, Luis Escala Rabadány Olga Odgers Ortiz, Mudando el hogar al norte... cit. p. 49 .

${ }^{15}$ Rafael Alarcón, Luis Escala Rabadány Olga Odgers Ortiz, Mudando el hogar al norte... cit. pp. 50 y ss.
} 


\section{I N T E GRACIÓN SOCIAL}

Las investigaciones de la integración social se han desarrollado bajo el paradigma de la asimilación o el multiculturalismo. Samuel Huntington analizó el grado en que los hispanos se asimilan a la sociedad norteamericana, estudiando el caso de la migración mexicana, la cual se caracteriza por los siguiente aspectos: 1) la migración de mexicanos hacia Estados Unidos se establece de forma muy sencilla ya que los inmigrantes sólo tienen que cruzar la frontera y como mucho un río, facilidad que se establece a partir de las vías de comunicación y transporte entre las dos naciones, lo que permite generar vínculos transnacionales entre ambos lugares; 2) "los inmigrantes mexicanos están concentrados en el suroeste de los Estados Unidos y forman parte de una sociedad mexicana contigua que se extiende desde Yucatán a Nevada ${ }^{16}$; 3) los inmigrantes mexicanos se resisten a la asimilación manteniendo su propia identidad y; 4) la migración tiene sus antecedentes en el Tratado de Guadalupe, en base al cual la parte norte de México fue anexada a los Estados Unidos, lo que significó que históricamente exista presencia de mexicanos en Estados Unidos.

Posteriormente, Huntington escribió en su libro ¿Quiénes somos? un capítulo sobre "El desafío hispano" donde señaló que la migración mexicana amenazaba a los Estados Unidos, argumentando que dicha migración podría acabar con la cultura dominante, identificada en su mayoría como una sociedad de personas “anglo-protestantes” y de tez blanca. Puntualizó que la migración de mexicanos hacia Estados Unidos difiere totalmente de las experiencias de flujos migratorios de principios del siglo XX y de

\footnotetext{
${ }^{16}$ Samuel Huntington, El choque de civilizaciones y la reconfiguración del orden mundial, Buenos Aires, Paidós, 2001, p. 198.
} 
los actuales, debido a la combinación de seis factores: 1) Contigüidad; 2) Número; 3) Ilegalidad; 4) Concentración regional; 5) Persistencia; y 6) Presencia histórica. Factores que indican que los inmigrantes mexicanos no se integraban socialmente al lugar de establecimiento, sobre todo, cuando se analizaban las variantes del dominio del idioma, la escolaridad, el estado migratorio, los usos de servicios públicos y la presencia de redes sociales ${ }^{17}$.

Esta generalidad de la migración mexicana ha sido puesta en duda, sobre todo, cuando el proceso de integración se concibe como una multiplicidad de estrategias que derivan en resultados exitosos, tal como lo indican factores referentes al estado migratorio y a los períodos de residencia en los Estados Unidos. Este es el caso de los mexicanos residentes en Los Angeles, los cuales sin importar su estado migratorio, prefieren como hogar, el lugar de establecimiento sobre su país de origen, básicamente, porque rechazan el sistema político mexicano y la ola de violencia que azota al país $^{18}$. No obstante, frente a la nueva realidad que viven los inmigrantes en Estados Unidos y con la efervescencia del cambio de gobierno que se vive en México, con la llegada de Andes Manuel López Obrador a la Presidencia de México, estos inmigrantes mexicanos en Los Angeles manifestarían alguna esperanza de retornar a su lugar de origen o seguirían fundamentado el lugar de establecimiento como su hogar.

\section{INTEGRACIÓN CULTURAL}

Los estudios de la integración cultural analizan el problema que surge cuando los recién llegados ponen en riesgo la identidad de la sociedad dominante. Como se abordó en párrafos anteriores, Huntington argu-

${ }^{17}$ Cfr. Samuel Huntington, "El desafío hispano”, en Letras libres, Vol. 6, № 64, 2004, pp. 12-23.

${ }^{18}$ Cfr. Rafael Alarcón, Luis Escala Rabadány Olga Odgers Ortiz, Mudando el hogar al norte... op. cit. 
mentaba que los migrantes mexicanos no se asimilan a la sociedad estadounidense debido a la cultura que tienen, por el contrario, la identidad de los migrantes mexicanos y, muy especialmente los inmigrantes de origen indígena, fortalecen su etnicidad y la reconfiguran manteniendo vínculos estrechos entre los lugares de destino y los lugares de origen, como bien se ilustra con las características que conforman la comunalidad y la transpertenencia indígena ${ }^{19}$.

Kymlicka ${ }^{20}$ proporcionó una nueva perspectiva dejando de lado el tema de integración y asimilación cultural, para dar cabida al reconocimiento de los derechos culturales y políticos de las minorías étnicas, buscando modificar y rediseñar las instituciones públicas del Estado. Incluso, algunos trabajos sobre integración cultural se refieren al análisis de cómo las políticas públicas deben generar igualdad social, prevenir la discriminación y la segregación social, a través del acomodo de las minorías étnicas en las instituciones públicas.

Mientras que Alarcón y et.al. propusieron analizar la integración cultural a la luz de los procesos y estrategias que desarrollan los inmigrantes en el lugar de llegada, a través de dos variantes: la que tiene que ver con la búsqueda del reconocimiento y, por el otro lado, la que tiene que ver con la búsqueda de la “asimilación mediante la disolución de las diferencias que obstaculizan la movilidad social [a través del análisis de los indicadores sobre la] identidad y el sentido de pertenencia, religión, segregación residencial y percepción de la alteridad”21, así como el uso del idioma y las trayectorias de vida.

\footnotetext{
${ }^{19}$ Cfr. Saúl Ramírez Sánchez, El sentido de transpertenencia de los mixes migrantes de Tlahuitoltepec, Oaxaca, México, Comisión Nacional para el Desarrollo de los Pueblos Indígenas, 2010; "Los cargos comunitarios y la transpertenencia de los migrantes mixes de Oaxaca en Estados Unidos”, en Migraciones internacionales, 2006, Vol. 3, № 3, 2006, pp. 31-53.

${ }^{20}$ Cfr. Will Kymlicka, Ciudadania multicultural... op. cit.

${ }^{21}$ Rafael Alarcón, Luis Escala Rabadány Olga Odgers Ortiz, Mudando el hogar al norte... cit. p. 64 .
} 


\section{INTEGRACIÓN POLÍTICA}

La integración política se ha analizado a la luz de la problemática que tiene que ver, por un lado, con la condición política de los inmigrantes y, por el otro lado, con el papel que juega el Estado, tanto en los lugares de destino como de los lugares de origen. Pasando por las reflexiones sobre el tema de soberanía, la noción de ciudadanía como membresía a la comunidad política, así como por el reconocimiento de los derechos civiles, políticos, económicos y culturales de los inmigrantes ${ }^{22}$.

Zolberg mencionaba que la migración internacional es un fenómeno social que implica no sólo la movilidad de un lugar a otro, sino que deriva de la especificidad de la organización del mundo en un conglomerado de Estados soberanos mutuamente excluyentes. Este sistema de Estados denominado Westfeliano comprende a la migración como la transferencia de una persona de un lugar a otro, es decir, de la jurisdicción de un Estado a la de otro y el eventual cambio de pertenencia y de reconfiguración identitaria de una comunidad política a otra, la cual puede ser incluyente aunque generalmente es excluyente, discriminatoria y xenófoba ${ }^{23}$. En este tenor, la integración de los inmigrantes es un proceso inherentemente político, y las políticas pertinentes abarcan no sólo la regulación del movimiento hacia afuera y hacia adentro (cruce de fronteras estatales), sino también de las reglas que rigen la adquisición, el mantenimiento, la pérdida o la renuncia voluntaria a la afiliación o membresía en todos sus aspectos políticos, sociales, económicos y culturales.

${ }^{22}$ Cfr. Will Kymlicka, La política vernácula. op. cit.; Francisco Ibarra Palafox, Minorías etnoculturales... op. cit.

${ }^{23}$ Cfr. Aristide Zolberg, A Nation by Design: Immigration Policy in the Fashioning of America, Harvard University, 2006, p. 11. 
Las acciones públicas de integración política dirigidas a los inmigrantes dan la oportunidad o las restricciones para obtener la naturalización en un Estado, de lograr una ciudadanía dual o una ciudadanía supranacional. Acciones que llevan en el fondo a la discusión y al debate sobre la problemática propuesta por las “teorías de la erosión” y de la expansión de la soberanía de los Estados, como la entidad encargada de otorgar ciudadanía ${ }^{24}$, es decir, en el fondo de esta idea está el debate que se tiene sobre el sistema soberano de Estado, el cual puede ser clasificado como: Westfeliano, Post-Westfeliano o Neo-Westfeliano ${ }^{25}$.

Otras propuestas sobre la integración política de los inmigrantes han estudiado el tema electoral, específicamente lo relacionado con el sufragio, tanto en la sociedad receptora como en el lugar de origen. De la misma manera, también se han realizado investigaciones con las temáticas que tienen que ver con los niveles de naturalización de los inmigrantes en los lugares de destino, así como su participación política en manifestaciones o movilizaciones de reconocimiento de derechos, con la percepción y la participación política en ambos lugares.

En resumen, esta fotografía descrita de manera general, da vista de las principales temáticas de estudios sobre los diversos ámbitos de integración de los inmigrantes a la sociedad receptora. A continuación se abordará el tema de la integración jurídica, a la luz de la sociología del derecho, lo que conlleva cuestionarnos ¿cuál es el análisis que realiza esta disciplina respecto al tema de la integración? ¿cómo se concibe el problema de la integración de los inmigrantes en la dimensión socioju-

\footnotetext{
${ }^{24}$ Cfr. Thomas Faist, "Migración y teorías de la ciudadanía”, en Pablo Mateos (Ed.), Ciudadanía múltiple y migración: perspectivas latinoamericanas, México, CIDE / CIESAS, 2015 , p.35.

${ }^{25}$ Cfr. David Abraham, "Law and Migration: Many constants, few changes", en Caroline B. Brettel y James J. Hollifield (Eds.), Migration Theory: Talking across discipline, New York, Routledge, 2015, p. 299.
} 
rídica? ¿cuál es la diferencia de la integración en general respecto a la integración jurídica de los inmigrantes? ¿porqué estudiar la integración jurídica de los inmigrantes y, en especial, la de los inmigrantes indígenas mexicanos en la sociedad receptora?

\section{LA INTEGRACIÓN JURÍDICA. UNA PROPUESTA}

Antes de definir la noción de integración jurídica es importante aclarar que esta idea no plantea si está a favor o en contra de la asimilación o del multiculturalismo ${ }^{26}$, al contrario, lo único que se demanda es que los inmigrantes indígenas sean tratados equitativamente, en igualdad de derechos y oportunidades, por lo que se requiere que el Estado se comprometa a salvaguardar los derechos de las personas y a establecer las políticas jurídicas encaminadas a que los inmigrantes tengan acceso a la justicia, lo que daría como resultado un marco de instituciones justas en una era de recesiones y restricciones ${ }^{27}$.

Esta perspectiva habrá que ubicarla en los terrenos de la sociología del derecho, ciencia que en nuestro país es relativamente joven a la luz de los productos colectivos que se han desarrollado, dejando de lado los intereses académicos individuales que siempre han existido. Mientras que, a partir de los años noventa hubo un resurgimiento de los estudios

${ }^{26}$ Cfr. Silvia Pedraza, "Assimilation or Transnationalism? Conceptual Models of the Immigrant Experience”, in Ram Mahalingam, Ed., The Cultural Psychology of Immigrants, Mahwah, NJ, Lawrence Erlbaum, 2006; Christian Joppke y Ewa Morawska (Eds.), Toward Assimilation and Citizenship: Immigrants in Liberal Nation-States. Migration, Minorities and Citizenship, London, Palgrave Macmillan, 2014; Ugur Gulay Goksel, Integration of Immigrants and the Theory of Recognition, Estambul, Palgrave, Macmillan, 2018.

${ }^{27}$ Cfr. David L. Leal, Nestor P. Rodríguez y Gary P. Freeman, "Introduction: The New Era of Restriction", en Migration in an Era of Restriction and Recession, Springer, Cham, 2016, pp. 1-23. 
de la sociología del derecho ${ }^{28}$ en Estados Unidos, Canadá e Inglaterra, los cuales ponían atención especial a las investigaciones sobre políticas públicas jurídicas, así como en la cultura jurídica, la legislación, la legitimidad, la profesión jurídica y la judicialización, incluyendo los estudios comparativos y los trabajos históricos y culturales.

Así pues, el tema de la integración jurídica de los inmigrantes indígenas a la luz de la sociología del derecho se debe comprender como un proceso "bidireccional". Teniendo, por un lado, a los inmigrantes que se incorporan a la sociedad de llegada y, por el otro lado, al Estado de recepción y a la misma sociedad estableciendo medidas para integrar a los inmigrantes. En esta noción existe un cambio de paradigma debido a que la responsabilidad de incorporación a la sociedad de establecimiento no solamente recae en el inmigrante sino en la sociedad misma y sus instituciones.

Este cambio de paradigma, de un proceso unidireccional a un proceso bidireccional, es muy importante, debido a que esta postura rompe con la idea de la asimilación y el multiculturalismo, pues la integración ya no sería responsabilidad solamente del inmigrante, ni sería una cuestión natural y, mucho menos, evolutiva, sino todo lo contrario, el proceso de integración no sería el fin sino el medio para lograr la inclusión en el lugar de establecimiento.

${ }^{28}$ Esta disciplina estudia el derecho en cuanto a la modalidad de la "acción social", esto significa que es una herramienta científica que ve al derecho como un producto social, de luchas, de acuerdos, de política. La relevancia de la perspectiva radica en encontrar al derecho en el estudio de la sociedad con campos en disputas en esa realidad social donde hay intereses, políticos, partidos, excluidos e incluidos, procesos de dominación excluyente y muchas veces injustas o justas. Cfr. Vincenzo Ferrari, Derecho y Sociedad. Elementos de Sociología del Derecho, Colombia, Universidad Externado de Colombia, Trad. Santiago Perea Latorre, 2004; "Cincuenta años de Sociología del Derecho. Un balance”, en Boletín Mexicano de Derecho Comparado, Año XLIII, № 129, 2010, pp. 1459-1571; Primera Lección de Sociología del Derecho, México, Instituto de Investigaciones Jurídicas, UNAM, Trad. Héctor Fix-Fierro, 2015. 
Esta visión de integración de los inmigrantes indígenas en el ámbito jurídico tiene como principio reconocerlos como sujetos de derecho, quienes cuentan con voluntades libres de incorporación a la sociedad receptora, por lo que no existe un mandato para que los inmigrantes adopten la cultura dominante en la sociedad receptora en términos de la asimilación o el multiculturalismo. Al contrario, lo importante es comprender a la integración jurídica ${ }^{29}$ como el derecho a tener derechos, lo que se traduciría en la exigibilidad de sus derechos y en la inclusión de los inmigrantes a la sociedad receptora en términos de un trato igualitario y de respeto. Como dice De Lucas ${ }^{30}$, "lo contrario de exclusión es integración. Pero ese es un término vago, salvo que lo concretemos: integración es igualdad. Lo que sucede es que no hay igualdad si nos limitamos a la lucha contra la discriminación y olvidamos la inclusión, que es reconocimiento como sujetos, respeto y participación”.

\footnotetext{
${ }^{29}$ Solé y compañía propusieron tres modelos de integración jurídica: 1) modelo de inclusión/exclusión social, que considera la inmigración como un hecho temporal y concede derechos civiles y sociales a inmigrantes pero les niega la ciudadanía; 2) modelo de integración jurídica se refiera a la naturalización, la cual considera una inmigración definitiva; y 3) modelo de integración es el de ciudadanía, la cual favorece la integración jurídica. Estos modelos muestran que los inmigrantes en la sociedad receptora buscan la ciudadanía, a fin de que pueda existir una integración jurídica por parte de los inmigrantes, lo que significa en el fondo una correlación inherente entre el reconocimiento jurídico de los inmigrantes con la noción política de ciudadanía, donde la fusión de lo jurídico-político traerá como resultado la integración jurídica de los inmigrantes en la sociedad receptora. Estos escenarios tienen sus limitantes y una es que la integración jurídica se pone bajo la responsabilidad de los inmigrantes. Asimismo, la propuesta da por sentado que la integración jurídica de los inmigrantes se da automáticamente con la obtención de la ciudadanía, sin embargo, este es un trámite administrativo que no garantiza dicha integración ni que tenga un nivel máximo de incorporación al lugar de establecimiento, quizá pueda haber un inmigrante que tenga una mayor integración jurídica sin haber obtenido la ciudadanía. Cfr. C. Solé et al., "El concepto de integración... cit. p. 27.

${ }^{30}$ Javier De Lucas, Javier, "Inmigrantes. Del estado de excepción al Estado de derecho”, en Oñati Socio-Legal Series, Vol. 1, № 3, 2011, p. 9.
} 
La definición de integración jurídica que se utilizará para comprender la incorporación de los inmigrantes indígenas tiene que ver con las modalidades y acciones que realizan estos sujetos para pertenecer a la sociedad receptora. Esto significa comprender la integración jurídica no como un estadio a alcanzar sino como un proceso en dos direcciones: 1) la que reconoce a los "inmigrantes" y a sus descendientes como sujetos de derecho que se van incorporando al lugar de destino a través de diversas modalidades o estrategias que se negocian y se establecen en la arena pública para integrarse, la cual forma parte de su cultura jurídica; y 2) la que se refiere a la obligatoriedad del "Estado" para diseñar e implementar políticas jurídicas como una forma de acceder a la justicia, para acomodar a los inmigrantes en la sociedad receptora, incluso desde el lugar de origen, a fin de establecer acciones públicas que busquen lograr la inclusión, la igualdad y la no discriminación de estos sujetos de derecho público.

Esta definición fija una postura que en el fondo está conminando a una corresponsabilidad entre los propios sujetos que se movilizan como las autoridades del Estado de expulsión y de recepción. Y si fuéramos más allá de lo nacional, esta perspectiva tendría que incluir a los organismos supranacionales, a fin de salvaguardar los derechos y la integración jurídica de los inmigrantes tanto regulares como irregulares. Esta noción de integración jurídica será complementada por dos unidades de análisis que nos ayudará a comprender y a explicar los niveles de incorporación de los inmigrantes indígenas a la sociedad receptora: "la cultura jurídica y el acceso a la justicia como política jurídica".

La cultura jurídica es un concepto paraguas que ayudará a analizar y comprender a los inmigrantes indígenas en la sociedad receptora independientemente de su estado migratorio, la cual hay que concebirla como un factor que modula el funcionamiento institucional de la inte- 
gración jurídica. Mientras que el acceso a la justicia como política jurídica será la unidad de análisis que nos permitirá explicar el segundo camino de la definición de la integración jurídica, es decir, el punto de vista del rol que juega el Estado, en este caso el gobierno de California, en el diseño e implementación de políticas de acceso a la justicia para el pleno ejercicio de derechos de estos inmigrantes.

Bajo este contexto, la pregunta que deberíamos formularnos es $\dot{\mathrm{C}}^{\mathrm{en}}$ qué medida la cultura jurídica y el acceso a la justicia como política jurídica contribuyen a explicar los niveles de incorporación de los inmigrantes indígenas mexicanos a la sociedad estadounidense del Condado de San Diego, California?, es decir, ¿cuáles son los niveles de integración jurídica de los inmigrantes indígenas mexicanos establecidos en el Condado de San Diego, independientemente, de su estado migratorio? Con estas cuestiones estamos dando por sentado que existe una integración jurídica por parte de los inmigrantes a la sociedad receptora, lo que significa que existen actitudes, conocimientos y comportamientos de los inmigrantes indígenas sobre el derecho que les permite integrase a la sociedad receptora por lo que implementan diversas estrategias y modalidades para tener derecho a obtener derechos en el lugar de establecimiento, aunado a la corresponsabilidad del Estado para garantizar el acceso a la justicia a través de las políticas jurídicas diseñadas e implementadas a los inmigrantes, independientemente de su estado migratorio.

Uno de los principios que forma parte de la cultura jurídica y que lo refrenda el Poder Judicial del Estado de California en Estados Unidos, es el respeto que deben de tener todas sus Cortes para todos los individuos, sin importar el idioma que hablen las personas ni tampoco el lugar dónde nacieron. Este principio es relevante para la propuesta de integración jurídica, pues denota en el fondo una cultura jurídica que 
tiene como principio la inclusión y el acceso a la justicia, lo que significa que sin importar el estado migratorio de los inmigrantes indígenas, éstos tienen derecho a ser respetados y a recibir un trato igualitario. En este marco, para la justicia californiana no debería importar si los inmigrantes tienen un estado migratorio regular o irregular.

\section{LA CULTURA JURÍdicA COMO PARTE DE LA INTE- GRACIÓN JURÍDICA}

Los estudios de la integración jurídica, desde la óptica de la sociología jurídica, han abordado el tema de la cultura jurídica en sus diversos aspectos. Uno de ellos es el relacionado con el tema de la globalización, misma que explica, por un lado, las transacciones comerciales internacionales y, por el otro, el desarrollo y trabajo de los despachos internacionales de $\operatorname{abogados}^{31}$.

Gessner advierte que la "integración jurídica cultural” es una consecuencia de la “integración jurídico estructural”. Esta idea la desarrolla a la luz del derecho comunitario de Europa, donde se están unificando

${ }^{31}$ La primera linea de trabajo se refiere a las transacciones comerciales internacionales en donde existe un sistema de normas autónomas, regulaciones no jurídicas, creadas por las asociaciones comerciales, bancarias y las instituciones supranacionales, denominada frecuentemente como Lex Mercatoria. El ejemplo empírico más conocido es el de Gessner, quien explicó la regulación autónoma que tienen los judíos sobre el comercio mundial de diamantes en bruto. Asimismo, señala que para entender la cultura jurídica es pertinente conocer el desempeño de los despachos internacionales de abogados, los cuales tienen un papel importante en el proceso de surgimiento del derecho global, en términos de que llegan a ser instituciones con órdenes normativos informales que regulan el cumplimiento contractual de manera muy eficiente y con muy alto nivel de eficiencia y eficacia, siendo un claro ejemplo la conformación de clanes familiares chinos y la implementación de la relación guanxi. Cfr. Volkmar Gessner, El otro derecho comparado. Ensayos sobre cultura y seguridad jurídicas en la era de la globalización, México, Instituto de Investigaciones Jurídicas, UNAM, Trad. y Ed. Héctor Fix-Fierro, 2013, pp. 80-83. 
los sistemas jurídicos de los países miembros. De hecho, menciona que la integración jurídica es la principal preocupación de la Comisión de la Comunidad Europea, la cual se ha convertido también en un tema central de la ciencia jurídica ${ }^{32}$. Esto significa que la integración jurídica va más allá de lo formal o institucional, pues concibe a la cultura jurídica como un concepto de prácticas jurídicas no formales, patrones de interpretación (valores y actitudes) y rutinas de comportamiento en relación con el derecho, así como con las instituciones sociales informales que forman parte del proceso de implementación jurídica. Esta definición de cultura jurídica se enfoca a las prácticas jurídicas no formales como las que pudieran experimentar los inmigrantes indígenas en la sociedad receptora, es decir, los inmigrantes se conducen de acuerdo a la ley, la conocen, siendo las prácticas jurídicas en la que se conducen formales o informales.

Otra propuesta sugiere entender la integración jurídica a la luz de la cultura jurídica. Merryman desagrega este término en dos tipos de cultura jurídica: una externa y otra interna. La primera se refiere al conjunto de "actitudes culturales, firmemente arraigadas y sostenidas, que determinan la manera de en que los actores externos (outsiders) -aquellas personas que no desempeñan ningún rol de forma regular en el sistema jurídico- perciben y definen el sistema jurídico y esperan que sea utilizado o no lo sea" ${ }^{33}$. Mientras que la cultura jurídica interna es concebida como las "actitudes dentro del sistema jurídico, es decir, las actitudes de los actores (insiders) internos, también profundamente arraigas y firme-

\footnotetext{
32 Volkmar Gessner, El otro derecho comparado... cit. pp. 31 y ss.

${ }^{33}$ John Henry Merryman, "Memoria de SLADE”, en Héctor Fix-Fierro, Lawrence M. Friedman y Rogelio Pérez Perdomo (Eds.), Culturas Jurídicas Latinas de Europa y América en tiempos de Globalización, México, Instituto de Investigaciones Jurídicas, UNAM, 2003, p. 762.
} 
mente sostenidas" ${ }^{34}$.

Lawrence Friedman sigue esta corriente de pensamiento y define la cultura jurídica externa de acuerdo al nivel de conocimientos de los individuos sobre el derecho, tomando en cuenta sus patrones y actitudes de comportamiento respecto a lo jurídico ${ }^{35}$. Bajo esta tesitura, Meneses retomó la definición para desagregarla en dos áreas de estudio: 1) los estudios sobre cultura jurídica de los individuos y; 2) los estudios que se refieren a los trabajos sobre conciencia jurídica. Ambos tipos de estudios sociojurídicos se localizan en los terrenos del debate de la cultura jurídica externa $^{36}$.

Estas investigaciones se caracterizan por su aproximación cultural, las cuales se realizan con material estadístico; entrevistas estructuradas o cerradas; se enfocan a las opiniones de los individuos comunes respecto al derecho y al sistema jurídico; estructuran los resultados regularmente en tablas estadísticas o bases de datos correlacionados; analizan los resultados a la luz de consideraciones generales y abstractas; y concluyen "sus análisis en términos sociales orgánicos" ${ }^{37}$. Mientras que los estudios sobre conciencia jurídica se refieren a las investigaciones que se realizan en base a trabajo de campo, investigaciones empíricas que aplican enfoques cualitativos; que se centran en los servicios legales y los derechos específicos de los individuos; utilizan en sus análisis niveles agregados como indicadores generales; y presentan las consideraciones finales con apego

\footnotetext{
${ }^{34}$ John Henry Merryman, "Memoria de SLADE... op.cit.

${ }^{35}$ Lawrence M. Friedman, The legal system: A social science perspective, Russell Sage Foundation, 1975, p. 223 y ss.

${ }^{36}$ Rodrigo Meneses, "Del acceso a la justicia a la cultura jurídica externa. Una transición teorico-metodológica”, en J. Antonio Caballero Juárez, Hugo A. Concha Cantú, Héctor Fix-Fierro y Francisco Ibarra Palafox, Sociología del Derecho. Culturas y Sistemas furídicos Comparados. Regulación, Cultura Jurídica, Multiculturalismo, Pluralismo Furídico y Derechos Humanos, Vol. II, México, Instituto de Investigaciones Jurídicas, UNAM, 2010, p. 129.

${ }^{37}$ Rodrigo Meneses, "Del acceso a la justicia a la cultura jurídica... cit. p. 130.
} 
a los hallazgos sociales encontrados ${ }^{38}$.

En cambio, Nelken apuesta por una definición más amplia de la cultura jurídica, definiéndola como una "forma de describir algunos patrones, relativamente estables, de conductas y actitudes sociales jurídicamente orientadas" ${ }^{39}$. Este investigador busca diferenciar en los diversos estudios de la cultura jurídica dos cuestiones: 1) como explicación y, 2) como algo que está siendo explicado ${ }^{40}$. La primera se refiere, por un lado, a la decisión de utilizar el derecho como un factor que conforma el sistema jurídico (estudios sobre conciencia jurídica), y, por el otro, a la influencia ejercida por la cultura jurídica, por ejemplo: un patrón específico de actitudes, usos y discursos sobre el derecho. Mientras que de los trabajos 'relacionados a algo que necesita ser explicado' se desprenden dos opciones: la primera opción se refiere a las posturas que tienden a explicar la conciencia jurídica, el por qué las personas deciden utilizar o no el derecho y, la segunda, busca explicar por qué las unidades específicas de cultura jurídica tienen diferentes patrones.

En este contexto, la propuesta para analizar la integración jurídica se ubica en los terrenos de la cultura externa como explicación que modula el funcionamiento institucional a través del ejercicio de los derechos y del acceso a la justicia como política jurídica. No obstante, esta comprensión debe tomar en cuenta que los inmigrantes indígenas mexicanos asentados en la sociedad estadounidense transitan, al menos, en tres diferentes culturas jurídicas: la estadounidense, la mexicana ${ }^{41}$ y la indígena.

${ }^{38}$ Rodrigo Meneses, "Del acceso a la justicia a la cultura jurídica... cit. p. 131.

${ }^{39}$ David Nelken, "Repensando el concepto de cultura jurídica”, J. Antonio Caballero Juárez, Hugo A. Concha Cantú, Héctor Fix-Fierro y Francisco Ibarra Palafox, Sociología del Derecho. Culturas y Sistemas Furídicos Comparados. Regulación, Cultura Jurídica, Multiculturalismo, Pluralismo Furídico y Derechos Humanos, Vol. II, México, Instituto de Investigaciones Jurídicas, UNAM, 2010, p. 143.

${ }^{40}$ David Nelken, "Repensando el concepto de cultura jurídica... cit. p. 163.

${ }^{41}$ La cultura jurídica estadounidense forma parte de su sistema jurídico, la cual tiene dos características en términos formales y estructurales, estos es, la revisión judicial y 


\section{Esta última, se caracteriza por tener un derecho indígena sustentado en la oralidad, con una estructura basada en el sistema de cargos cívico-reli- gioso, un sistema normativo que busca solucionar conflictos, procurar e impartir justicia cuyo fin último es el bien común o el buen vivir, es decir,}

el federalismo. La revisión judicial es un "elemento estructural que responde a la conciencia que los estadounidenses tienen de sus derechos, al individualismo, al miedo a la concentración del poder, a la desconfianza a la centralización y a la tradición estadounidense de un gobierno disperso y fragmentado", lo que significa que los individuos o los grupos podrán exigir justicia. El federalismo estadounidense se concibe como una república federal formada por cincuenta estados, cada uno con sus respectivos sistemas jurídicos que coexisten con el sistema jurídico nacional, además de Puerto Rico (con un sistema jurídico de derecho continental), las Islas Vírgenes, Guam y los sistemas jurídicos de las tribus nativas estadounidenses. En suma, tanto la revisión judicial como el federalismo se encuentran tan arraigados que conforman parte de la cultura jurídica estadounidense. La cultura jurídica mexicana se caracteriza por pertenecer al sistema jurídico del derecho continental o civil law, el cual tiene gran influencia del derecho romano. En esta tradición jurídica, los jueces solo interpretan las leyes, ya que las normas se encuentran codificadas y los jueces no tienen facultades para sumar o restar al derecho, dado que se encuentra estipulado en las leyes, a diferencia del derecho estadounidense donde el derecho es creado por los jueces, que son abogados practicantes y políticamente activos. En tanto que los jueces del derecho continental son servidores públicos y su sistema carece de jurado. México ha sufrido cambios en su infraestructura jurídica en las últimas cuatro décadas, pasando de un sistema tradicional a uno más moderno y racional. Estos cambios jurídicos se debieron a las transformaciones en la política económica del país, en la efectividad de la aplicación de la ley, en la creación de un marco institucional nuevo y a un sistema jurídico más abierto al derecho internacional, estableciéndose así una nueva cultura jurídica con una "creciente conciencia sobre los derechos fundamentales, pero también un desconocimiento generalizado de la Constitución y otras leyes importantes; [así como por] la existencia de un alto grado de desconfianza hacia las instituciones y los profesionales del derecho". Estas distinciones de la cultura jurídica estadounidense y la mexicana son muy generales, sin embargo, nos brindan indicios de una cultura jurídica mexicana basada en el formalismo, mientras que la cultura jurídica estadounidense se sustenta en su pragmatismo estadounidense. Cfr. Sergio López-Ayllón y Héctor Fix-Fierro, “¡Tan cerca, Tan Lejos! Estado de derecho y cambio jurídico en México”, en Héctor Fix-Fierro, Lawrence M. Friedman y Rogelio Pérez Perdomo (Editores), Culturas juridicas latinas de Europa y América en tiempos de globalización, México, Instituto de Investigaciones Jurídicas, UNAM, 2003, pp. 503604; Héctor Fix-Fierro Sergio López-Ayllón, "Comunicación entre culturas jurídicas: los paneles binacionales del Capítulo XIX del TLCAN", en Revista de Derecho Privado, 1997, Vol. 8, № 23, pp. 19-62. 
un sistema sustentado en principios axiológicos y jurídicos, de lo que es y debe ser. Si bien es cierto que es difícil diferenciar en las comunidades indígenas las esferas de lo político, lo religioso o lo cultural ${ }^{42}$, también es cierto que sus principios de comunalidad muestran un complejo engranaje del sistema comunitario en el que se desarrollan y en el que han sobrevivido, durante muchos siglos, en sus tierras y territorios que cada vez son más reducidos y más anhelados para la ejecución de megaproyectos.

La cultura jurídica indígena sigue basándose en la asamblea comunitaria como la institución y el espacio público en donde se dirimen los asuntos de la comunidad y se toman decisiones, legitimadas y validas por la mayoría ${ }^{43}$. Estos conocimientos, actitudes y comportamientos que tienen los indígenas, al llegar a la sociedad del Condado de San Diego, se reconfiguran, lo que significaría explicar las diferencias y similitudes de las culturas jurídicas por donde transitan estos inmigrantes, es por ello, que se eligió como una unidad de análisis a la cultura jurídica, la cual ayudará a comprender y explicar la integración jurídica de estos inmigrantes indígenas a la sociedad estadounidense. Estos indígenas inmigrantes comparten una conciencia jurídica que se basa en la auto-identificación

\footnotetext{
${ }^{42}$ Cfr. Héctor Fix-Fierro y Jacqueline Martínez Uriarte, "Chiapas: El escenario de una rebelión”, Revista de Estudios Políticos (Nueva Época), Núm. 84, 1994, pp- 165-179.

43 De hecho, el parteaguas a nivel internacional que marcó la cultura jurídica de los pueblos indigenas fue la movilización de representantes indígenas que hubo ante la sede de la Organización de las Naciones Unidas en Ginebra en 1977, dando cabida a la creación de mesas de trabajo, de organismos supranacionales y tratados para la salvaguarda de sus derechos. Mientras que a nivel nacional, los acontecimientos que marcaron un nuevo rumbo de la cultura jurídica indígena fueron las reformas constitucionales de 1992 y 2001, así como el surgimiento del Ejército Zapatista de Liberación Nacional (EZLN) en 1994, acontecimientos que pusieron sobre la mesa de la agenda nacional el tema del respeto a la libre-determinacion y a la autonomía, así como el pleno reconocimiento de sus derechos colectivos. Cfr. Saúl Ramírez Sánchez y José E. Victoria Saavedra, "La Constitución ante el derecho internacional indígena. Tarea pendiente del Estado mexicano”, en Alegatos, 2017, Vol. 31, № 97, pp. 641-656.
} 
como pertenecientes a un pueblo indígena migrante que reproduce y practica la autonomía en el extranjero. Una autonomía que se constituyó en mucho, por las asociaciones y las organizaciones étnicas y panétnicas desarrolladas en la comunidad indígena del lugar de establecimiento, lo que ha llegado a generar un activismo político y una autodefensa a las violaciones jurídicas, sociales, económicas y políticas ${ }^{44}$.

\section{ACCESO A La JUSTICiA Como POlítica JuRídica}

El acceso a la justicia como política jurídica es una forma de comprender la integración jurídica de los inmigrantes indígenas, la cual hay que entenderla como el estudio que se enfoca a los individuos y menos a los productores del servicio de la administración de justicia. Esto significa identificar problemas de carácter estructural, económico o tecnológico, que tienen que ser resueltos en términos de efectividad y racionalidad. Dentro de esta perspectiva “de las políticas jurídicas, el acceso a la justicia se ha identificado como un problema derivado de la carencia o escasa disposición de recursos financieros frente a los altos costos que, tanto en tiempo como en dinero, representa el proceso legal”45. Esta postura plantea que el acceso a la justicia como política jurídica es parte de un cambio jurídico, pero sobre todo, de un cambio social, el cual se apoya en el desarrollo económico y social, sustentado no solo en las instituciones sino en los actores sociales.

Con esta noción estamos pensando que los inmigrantes indígenas tienen derecho a demandar respeto sobre sus demás derechos humanos.

\footnotetext{
${ }^{44}$ Cfr. Carole Nagengast y Michael Kearney, "Mixtec Ethnicity: Social Identity, Political Consciousness, and Political Activism”, in Latin American Research Review, 1990, Vol. 25, № 2, pp. 61-91.

${ }^{45}$ Rodrigo Meneses, "Del acceso a la justicia a la cultura jurídica... cit. p. 126.
} 
En este tenor, el análisis sobre el acceso a la justicia como política jurídica se abordará a través del grado de protección o garantía que lleguen a tener estos sujetos de derecho a través de la implementación de políticas jurídicas o policies que se ejecuten en la sociedad receptora ${ }^{46}$, de ahí que surge la siguiente cuestión: de acuerdo a su contenido y fuerza argumentativa ¿hasta qué punto estas políticas jurídicas de acceso a la justicia o policies permiten o inhiben la integración jurídica en los inmigrantes indígenas? Para analizar esta cuestión se retomarán las leyes que se han promulgado en el Estado de California para proteger a los inmigrantes, independientemente del estado migratorio en el que se encuentren, las cuáles entraron en vigor el $1^{\circ}$ de enero del año 2018. Leyes que ahora forman parte del sistema legal de California y están consideradas como una respuesta frontal a la política federal de inmigración de Estados Unidos, la cual es considerada como anti-inmigrante, es decir, esta política de inmigración en la práctica y ejecución, es sumamente restrictiva y discriminatoria. Por tanto, estas nuevas leyes promulgadas en el Estado de

\footnotetext{
${ }^{48}$ Por ejemplo, en el año 2012 las autoridades educativas del Condado de Oxnard, California, resolvieron un conflicto de racismo y discriminación por el uso constante de los epítetos oaxaquita e indito que utilizaban los americanos o mexicanos para burlase en la escuela de los inmigrantes indígenas mexicanos. Ante ello, la Junta Escolar de dicho Condado estableció unas policies en sus reglamentos quedando prohibido dichos epítetos en las escuelas, a fin de evitar el bullying y la discriminación hacia los hijos de inmigrantes indígenas asentados en ese Condado. Cfr. Gaspar Rivera-Salgado, "De asociaciones de oriundos a movimiento transnacional: La evolución de las asociaciones de migrantes oaxaqueños en California”, en Luis Escala Rabadán, Asociaciones inmigrantes y fronteras internacionales, México, Colegio de la Frontera Norte, Colegio de San Luis Potosí, 2016, pp. 161-192; Laura Velasco Ortiz, "Liderazgos indígenas y política étnica transnacional en el contexto de las migraciones mexicanas a Estados Unidos”, en Escala Rabadán, Luis, Asociaciones inmigrantes y fronteras internacionales, Tijuana, Colegio de la Frontera Norte, San Luis Potosí, Colegio de San Luis Potosí, 2016, pp. 131-159; Equipo de Cronistas Oaxacalifornianos (ECO), Voces de jóvenes indígenas oaxaqueños en el Valle Central: Forjando nuestro sentido de pertenencia en California, California, University of California, Center for Collaborative Research for an Equitable California Research Report, Number 1, 2013.
} 
California que protegen los derechos de los inmigrantes han blindado al Estado, convirtiéndolo en un lugar "Santuario" para éstos ${ }^{47}$.

En la política de inmigración estadounidense se pueden observar, por un lado, una política federal para la inmigración sustentada en el "dilema de seguridad" ${ }^{48} \mathrm{y}$, por el otro lado, las policies para la convivencia con los inmigrantes en los estados y ciudades, las cuales pueden llegar a ser más restrictivas ${ }^{49}$ en sus derechos $\mathrm{o}$, al contrario, buscan implementar reglas

${ }^{49}$ Las leyes son: 1.- AB-291. Vivienda e inmigración. Contra amenazas de deportación a inquilinos; 2.- AB-299. Arrendadores no deberán pedir información migratoria de inquilinos; 3.- AB-21. Protección a estudiantes indocumentados; 4.- AB-343. Apoyo educativo a refugiados; 5.- AB-450. No redadas en centros de trabajo; 6.- AB-699. ICE fuera de las escuelas; 7.- SB-29. No más cárceles de ICE; 8.- SB-68. Ayuda financiera para más estudiantes; 9.- SB-156. Asistencia para la ciudadanía a inmigrantes en fuerzas armadas; 10.- SB-257. Cruzar la frontera para estudiar y; 11.- SB-54. Estado Santuario.

${ }^{50} \mathrm{El}$ dilema de seguridad se basa en que la inmigración desenfrenada es una amenaza seria a la seguridad nacional, la cual puede darse de tres formas: 1) Amenaza a la actual forma de gobierno, es decir, los inmigrantes socavan la democracia constitucional; 2) Amenaza al bienestar social, se refiere a que la inmigración socava la confianza social y las redes de seguridad social; 3) Amenaza a los individuos, se piensan que los inmigrantes traen enfermedades infecciosas o proliferan los crímenes y delitos. Frente a este contexto el gobierno responde con un control completo y discrecional, a fin de proteger a sus ciudadanos de las amenaza externas, aunque este poder también se vuelve una amenaza hacia sus mismos ciudadanos. Cfr. José Jorge Mendoza, The moral and political philosophy of immigration: Liberty, security, and equality, California, Lexington Books, 2016.

${ }^{51}$ Después del ataque al World Trade Center (1993) y a las Torres Gemelas (11 de septiembre de 2001), las políticas han sido alimentadas con actitudes anti-inmigrantes como fueron los caso de Florida, Arizona, Texas y California, donde se presentaron iniciativas que negaban los derechos sociales, de salud, educación y políticos a los inmigrantes (Proposición 187, SB1070, Proposición 200). También se han implementado programas, por un lado, de vigilancia fronteriza y, por el otro, programas operativos migratorios al interior de la Unión Americana. Los primeros tuvieron como objetivo disuadir la migración y controlar la frontera hacia México, tales como el programa Operation Hold the Line en la frontera de Juarez-El Paso, Operation Gatekeeper en el área de Tijuana-San Isidro, el programa de Río Grande Valley al sur de Texas y Nogales. Mientras que los programas hacia el interior del país se refieren a los operativos implementados a detener a inmigrantes irregulares o supuestamente criminales, como el Programa de Extranjeros Criminales, el Programa del Artículo 287 de la Ley de Inmigración y Nacionalidad, el Programa Nacional de Operaciones Fugitivas, el Programa de Comunidades Seguras, entre otros. Cfr. Doris Meissner et al., Inmigration Enforcement in the United States: The rise of a formidable machinery, Migration Policy Institute,Washington, D. C., 2013. 
que salvaguarden sus derechos, independientemente del estado migratorio en el que se encuentran los extranjeros en las sociedad receptora. Cabe resaltar que estas políticas jurídicas como acceso a la justicia pondrán al descubierto e ilustrarán la vulnerabilidad que tienen los inmigrantes indígenas, sobre todo, los que mantienen un estado migratorio irregular.

El Estado mexicano no cuenta con políticas jurídicas de acceso a la justicia para atender y apoyar a los inmigrantes indígenas ${ }^{50}$ asentados en Estados Unidos y Canadá, a pesar de que existe un mandato constitucional que salvaguarda los derechos de los indígenas migrantes tanto en el desplazamiento internacional como en la movilidad dentro del país, estipulado en la fracción VIII del Apartado B del Artículo $2^{\circ}$ de la Constitución Política de los Estados Unidos Mexicanos. Finalmente, con estas dos unidades de análisis se podrá explicar la integración jurídica a través de la construcción de un modelo que permita comprender los niveles de incorporación de los inmigrantes indígenas mexicanos a la sociedad estadounidense.

\section{MODELO DE INTEGRACIÓN JURÍDICA}

Las políticas jurídicas de acceso a la justicia en conjunto con la cultura jurídica de los inmigrantes indígenas conforman las dos unidades de análisis de la integración jurídica en el Estado receptor. En este contexto,

52 Existen algunos intentos de política jurídica que se han implementado, ejemplo de ello fue la denominada Plataforma Especial de Atención a Migrantes Indígenas (PEAMI), la cual se creó en 2010 por la Dirección General de Protección a Mexicanos en el Exterior y el Instituto de los Mexicanos en el Exterior y el Instituto Nacional de Lenguas Indígenas; a fin de establecer esquemas específicos para la atención y ayuda de la población mexicana indígena que reside en el exterior, particularmente en Estados Unidos y Canadá, conformándose un Directorio de Hablantes de Lenguas Indígenas Nacionales de Apoyo Consular para que colaborarán con los inmigrantes indígenas en las Cortes estadounidenses y/o en casos de emergencia consular. 
partimos del supuesto de que los inmigrantes indígenas mexicanos del Condado de San Diego son más propensos a tener una integración jurídica cuando éstos tienen mayor cultura jurídica (es decir, mayores conocimientos, comportamientos y actitudes frente al derecho estadounidense de la sociedad receptora) y un mayor acceso a la justicia como política jurídica (es decir, cuando el Estado receptor establece policies para la convivencia de las personas en la sociedad receptora independientemente del estado migratorio de las personas).

Esto significa que cuando los inmigrantes tengan mayores niveles de cultura jurídica y de acceso a la justicia se podrá inferir que existe un alto grado de integración jurídica, independientemente del estado migratorio en el que se encuentren estos sujetos de derecho, estos es, una mayor aplicabilidad y exigibilidad del derecho a tener derechos reflejará una inclusión más justa para los individuos en la sociedad receptora. En el fondo se está cuestionando ¿qué modelo de sociedad debería establecerse en la sociedad estadounidense para que los inmigrantes indígenas mexicanos se incorporen plenamente a la vida del lugar de llegada? Aunque también habrá que preguntarse ¿si los inmigrantes indígenas mexicanos buscan incorporarse a la sociedad receptora o no? y para los que buscan pertenecer al lugar de establecimiento ¿cuál es el nivel de incorporación en el que se encuentran?

Ante ello, se propone un nuevo modelo de integración jurídica para comprender y explicar los diversos escenarios de incorporación de los inmigrantes indígenas mexicanos a la sociedad estadounidense, así como sus niveles y grados de incorporación a dicha sociedad, mismos que pueden variar con base en el menor o mayor nivel de su cultura jurídica y del acceso a la justicia como política jurídica. Seguramente, la variable del estado migratorio de los indígenas podrá influir en los niveles de in- 
tegración jurídica de los inmigrantes indígenas, sin embargo, suponemos que no es factor determinante en la incorporación de los inmigrantes indígenas, puesto que California es un Estado Santuario.

La realidad social en la que se encuentran los inmigrantes es compleja, pues tenemos a inmigrantes irregulares que pueden llegar a tener una mayor integración jurídica, mientras que habrá inmigrantes indígenas que obtuvieron la ciudadanía estadounidense y, a pesar de ello, tengan un menor nivel de integración jurídica. Estos escenarios son un proceso de niveles y estrategias de exigencia de derechos donde los inmigrantes no buscan, siguiendo nuestro modelo, como fin último llegar al nivel más alto de incorporación a la sociedad receptora, sino el reconocimiento, la exigibilidad y aplicabilidad de sus derechos. En este tenor surge la cuestión de ¿cuáles son los elementos que explican las diferencias en la integración jurídica de los inmigrantes indígenas y, por ende, en sus niveles o grados de incorporación a la sociedad estadounidense? ¿a qué se debe que haya inmigrantes indígenas menos o más integrados? Sin duda, el derecho a tener derechos es la respuesta más inmediata, sin embargo, esta respuesta solo se podrá entender comprendiendo la cultura jurídica y el acceso a la justicia como política jurídica. Sin embargo, no hay que perder de vista la idea de retorno que tienen los inmigrantes indígenas a su comunidad de origen, la cual es una de las respuestas que explicarán el nivel de integración jurídica. 
Tabla 1. Modelo de Integración Jurídica

\begin{tabular}{|c|c|}
\hline $\begin{array}{c}\text { Tradicional } \\
\text { (Mayor Cultura Jurídica y poco o } \\
\text { nulo Acceso a la Justicia) }\end{array}$ & $\begin{array}{c}\text { Ideal } \\
\text { (Mayor Cultura Jurídica y mayor } \\
\text { Acceso a la Justicia) }\end{array}$ \\
\hline $\begin{array}{c}\text { Invisible } \\
\text { (Poca o nula Cultura Jurídica y } \\
\text { poca o nulo Acceso a la Justicia) }\end{array}$ & $\begin{array}{c}\text { Convencional } \\
\text { (Poca o nula Cultura Jurídica y } \\
\text { mayor Acceso a la Justicia) }\end{array}$ \\
\hline
\end{tabular}

Fuente: Elaboración propia.

* IJ. Integración Jurídica

Este modelo de integración jurídica basado en la concepción definida sobre la incorporación que tienen los inmigrantes indígenas en el lugar de establecimiento, es un proceso no necesariamente evolutivo, sino un proceso que aborda la idea del derecho a tener derechos a la luz de la cultura jurídica y el acceso a la justicia como política jurídica. El modelo presenta en el fondo una ambivalencia entre los principios axiológicos del derecho y los principios jurídicos, referentes al valor del derecho y a la justicia versus legalidad y seguridad jurídica. Principios que guían las unidades de análisis del modelo, tomando en cuenta que cada una de estas (cultura jurídica y acceso a la justicia como política jurídica) tendrán sus propios indicadores, como advertimos en párrafos anteriores. En el caso de la cultura jurídica nos referiremos al análisis de la conciencia jurídica que tienen los inmigrantes al sistema jurídico estadounidense, mexicano e indígena, así como la actitud que toman frente al derecho, de confianza o desconfianza. Y en el caso del acceso a la justicia como política jurídica se revisarán las policies que se promulgaron en el Estado de California, a fin de restringir o salvaguardar los derechos de los inmigrantes indígenas mexicanos. 
La combinación de éstos dos campos dan como resultado cuatro escenarios con diferentes niveles de integración jurídica: 1) invisible, 2) tradicional, 3) convencional e 4) ideal. La integración jurídica "invisible" se refiere a los inmigrantes indígenas que se establecen en la sociedad receptora y que no les interesa conocer el derecho estadounidense ni su andamiaje institucional, manteniendo la cultura jurídica del lugar de origen, es decir, renuncian al derecho a tener derechos y a su exigibilidad, y por lo regular no tienen acceso a la justicia como política jurídica porque el único interés que tienen, simplemente, es acumular dinero para regresarse a su lugar de origen. En tanto que la integración jurídica "tradicional” es una fotografía donde los inmigrantes tienen conocimientos de la cultura jurídica y el ordenamiento jurídico, pero muy pocas veces acceden a las políticas por temor a las consecuencias o al castigo (como puede ser la deportación en el caso de los inmigrantes irregulares).

En cambio, la integración jurídica "convencional” es aquella en donde los inmigrantes tienen poca cultura jurídica, pero tienen un nivel de acceso a la justicia como política jurídica debido a la seguridad jurídica que les brinda el derecho a tener derechos validado por el estado migratorio en el que se encuentran. Mientras que el tipo "ideal” de integración jurídica de los inmigrantes indígenas en la sociedad receptora se basa en el derecho a tener derechos, por ende, buscan la exigibilidad y aplicabilidad de dichos derechos, no solo en el conocimiento del sistema y el orden jurídico, sino en el acceso a la justicia como política pública. Lo que significa que los inmigrantes se interrelacionan en el lugar de establecimiento bajo los principios axiológicos, jurídicos y de derecho, independientemente del estado migratorio en el que se encuentren. 


\section{CONSIDERACIONES FINALES}

La integración jurídica de los inmigrantes indígenas debe ser analizada como un proceso "bidireccional", la cual puede ser entendida a través de dos unidades de análisis: 1) la cultura jurídica y 2) el acceso a la justicia como política jurídica. Este modelo permite comprender y explicar los grados o niveles de inclusión de estas personas en el lugar de establecimiento, los cuales se pueden ubicar en cualquiera de las cuatro categorías de integración jurídica: "Invisible, Tradicional, Convencional e Ideal”.

Cada uno de estos escenarios incluye una serie de indicadores tanto de la cultura jurídica como del acceso a la justicia como política jurídica, es decir, actitudes, conocimientos y comportamientos de los inmigrantes y las políticas aplicadas por el Estado, para comprender su derecho a tener derechos y su exigibilidad y aplicabilidad de las policies para la salvaguarda de los derechos de los inmigrantes indígenas. Suponemos que a mayor cultura jurídica y a mayor acceso a la justicia como política jurídica, mayor integración jurídica de los inmigrantes indígenas mexicanos a la sociedad estadounidense, lo que significa que a mayor aplicabilidad y exigibilidad de los derechos de humanos por parte de los inmigrantes, se alcanzará una inclusión justa de los individuos a la sociedad receptora.

\section{FUENTES \\ 1. BIBLIOGRAFIA}

Abraham, David, "Law and Migration: Many constants, few changes", en Caroline B. Brettel y James J. Hollifield (eds.), Migration Theory: Talking across discipline, Routledge, New York, 2015. 
Alarcón, Rafael et al., Mudando el hogar al norte. Trayectorias de integración de los inmigrantes mexicanos en Los Ángeles, Tijuana, El Colegio de la Frontera Norte, 2012.

Alba, Richard D., Ethnic identity: The transformation of white America, Yale University Press, 1990.

— Bright vs. blurred boundaries: Second generation assimilation and exclusion in France, Germany, and the United States", en Ethnic and Racial Studies, 2005, Vol. 28 № 1.

— 1 Victor Nee, "Rethinking assimilation theory for a new era of immigration”, en The International Migration Review, 1997, Vol. 31, №4.

- Remaking the American Mainstream: Assimilation and the New Immigration, Cambridge, Harvard University Press, 2005.

Alexander, Jeffrey C., "Theorizing the 'modes of incorporation': Assimilation, hyphenation, and multiculturalism as varieties of civil participation”, en Sociological Theory, 2001, Vol. 19, № 3.

De Lucas, Javier, "Inmigrantes. Del estado de excepción al Estado de derecho”, en Oñati Socio-Legal Series, 2011, Vol. 1, № 3.

Equipo De Cronistas Oaxacalifornianos (ECO), Voces de jóvenes indígenas oaxaqueños en el Valle Central: Forjando nuestro sentido de pertenencia en California, California, University of California, Center for Collaborative Research for an Equitable California Research Report, Number 1, 2013.

Faist, Thomas, "Migración y teorías de la ciudadanía", en Pablo Mateos (ed.), Ciudadanía múltiple y migración: perspectivas latinoamericanas, México, CIDE / CIESAS, 2015.

FAvell, Adrian, "Europe's identity problem", in West European Politics, 2005, Vol. 28, № 5 . 
Ferrari, Vincenzo, Derecho y Sociedad. Elementos de Sociología del Derecho, Colombia, Universidad Externado de Colombia, Trad. Santiago Perea Latorre, 2004 .

— “Cincuenta años de Sociología del Derecho. Un balance”, en Boletín Mexicano de Derecho Comparado, 2010, Año XLIII, № 129.

—, Primera Lección de Sociología del Derecho, México, Instituto de Investigaciones Jurídicas, UNAM, Trad. Héctor Fix-Fierro, 2015.

Fix-Fierro, Héctor y Jacqueline Martínez Uriarte, "Chiapas: El escenario de una rebelión”, en Revista de Estudios Políticos (Nueva Época), 1994, № 84.

— y Sergio López-Ayllón, “Comunicación entre culturas jurídicas: los paneles binacionales del Capítulo XIX del TLCAN”, en Revista de Derecho Privado, 1997, Vol. 8, No 23.

Fitzgerald, David, “The Sociology of International Migration”, en Caroline B. Brettel y James J. Hollifield (eds.), Migration Theory: Talking across discipline, New York, Routledge,2015.

Fox, Jonathan y Gaspar Rivera-Salgado (coords.), Indigenas mexicanos migrantes en los Estados Unidos, México, H. Cámara de Diputados, LIX Legislatura, Universidad de California, Santa Cruz, Universidad Autónoma de Zacatecas, Miguel Ángel Porrúa, 2004.

Freeman, Michael, Human Rights: An Interdisciplinary Approach, Cambridge and Malden, Polity, 2011.

Friedman, Lawrence M., The legal system: A social science perspective, Russell Sage Foundation, 1975.

Gandini, Luciana, ¿ Escapando de la crisis? Un estudio comparativo de trayectorias laborales de migrantes argentinos en la Ciudad de México y Madrid, Universidad Nacional Autónoma de México, 2015. 
GESSNER, Volkmar, El otro derecho comparado. Ensayos sobre cultura y seguridad juridicas en la era de la globalización, México, Instituto de Investigaciones Jurídicas, UNAM, Trad. y Ed. Héctor Fix-Fierro, 2013.

Glazer, Nathan, "We are all multiculturalists now”, en Kivisto, Peter, y Georganne Rundblad (eds.), Multiculturalism in the United States: Current issues, contemporary voices, Pine Forge Press, 2000.

GOKSEL, Gulay Ugur, Integration of Immigrants and the Theory of Recognition, Estambul, Palgrave, Macmillan, 2018.

Gordon, Milton, M., "Assimilation in America: Theory and Reality", en Daedalus, 1961, Vol. 90, № 2 .

- Assimilation in American Life: The Role of Race, Religion, and National Origins, New York, Oxford University Press, 1964.

Hartmann, Douglas y Joseph Gerteis, "Dealing with Diversity: Mapping Multiculturalism in Sociological Terms”, en Sociological Theory, 2005, Vol. 23, No. 2.

Huntington, Samuel, El choque de civilizaciones y la reconfiguración del orden mundial, Buenos Aires, Paidós, $4^{\underline{a}}$ reimpresion, 2001.

——, "El desafío hispano", en Letras libres, 2004, Vol. 6, № 64 .

Huerta Ochoa, Carla, "Principios y conflictos normativos a la luz de la tipología normativa de Dworkin”, en Olvera García, Jorge (coord.), La filosofia del Derecho de Ronald Dworkin. Críticas y aportaciones, México, UAEM, 2015.

JoPPKe, Christian, "The retreat of multiculturalism in the liberal state: theory and policy”, en The British fournal of Sociology, 2004, Vol. 55, № 2.

— y E., Morawska, "Integrating Immigrants in Liberal Nation-States: Policies and Practices”, en Toward Assimilation and Citizenship: Immigrants in Liberal Nation-States. Migration, Minorities and Citizenship, London, Palgrave Macmillan, 2014. 
Kivisto, Peter, "Robert E. Park's Theory of Assimilation and Beyond", en Peter Kivisto (ed.), The Anthem Companion to Robert Park, Anthem Press, 2017.

- y Thomas Faist, Beyond a Border: The Causes and Consequences of Contemporary Immigration, Los Angeles, Pine Forge Press, 2010.

Kymuicka, Will, Ciudadania multicultural. Una teoría liberal de los derechos de las minorías, España, Paidós, 1996.

——, La política vernácula. Nacionalismo, multiculturalismo y ciudadanía, España, Paidós, 2003.

Leal, David L. et al., "Introduction: The New Era of Restriction”, en Migration in an Era of Restriction and Recession, Springer, Cham, 2016.

Logan, John R. et al., "Immigrant enclaves and ethnic communities in New York and Los Angeles”, en American Sociological Review, 2002, Vol. 67, No. 2.

López-Ayllón, Sergio y Héctor Fix-Fierro, “¡Tan cerca, Tan Lejos! Estado de derecho y cambio jurídico en México”, en Héctor Fix-Fierro et al. (eds.), Culturas jurídicas latinas de Europa y América en tiempos de globalización, México, Instituto de Investigaciones Jurídicas, UNAM, 2016.

Meissner, Doris et al., Inmigration Enforcement in the United States: The rise of a formidable machinery, Migration Policy Institute,Washington, D. C., 2013.

Mendoza, José Jorge, The moral and political philosophy of immigration: Liberty, security, and equality, Califronia, Lexington Books, 2016.

Meneses, Rodrigo, "Del acceso a la justicia a la cultura jurídica externa. Una transición teorico-metodológica”, en Caballero Juárez, J. Antonio et al., Sociología del Derecho. Culturas y Sistemas furídicos Comparados. Regulación, Cultura Funídica, Multiculturalismo, Pluralismo Furídico y Derechos Humanos, Vol. II, México, Instituto de Investigaciones Jurídicas, UNAM, 2010. 
Merryman, John Henry, "Memoria de SLADE”, en Héctor Fix-Fierro et al., (eds.), Culturas Furídicas Latinas de Europa y América en tiempos de Globalización, México, Instituto de Investigaciones Jurídicas, UNAM, 2003.

Nagengast, Carole y Michael Kearney, "Mixtec Ethnicity: Social Identity, Political Consciousness, and Political Activism”, en Latin American Research Review, 2003, Vol. 25, № 2.

Nelken, David, "Repensando el concepto de cultura jurídica", Caballero Juárez, J. Antonio et al., Sociología del Derecho. Culturas y Sistemas Jurídicos Comparados. Regulación, Cultura Junídica, Multiculturalismo, Pluralismo Funídico y Derechos Humanos, Vol. II, México, Instituto de Investigaciones Jurídicas, UNAM, 2010.

Nevins, J., Operation Gatekeeper: The rise of the "illegal alien" and the remaking of the US-Mexico boundary, New York, Routledge, 2001.

Ortiz Ahlf, Loretta, Derechos humanos de los indocumentados, México, Tirant lo Blanch, 2013.

PARK, Robert E., "Racial assimilation in secondary groups with particular reference to the Negro", en American fournal of Sociology, 1914,Vol. 19, № 5.

— "Human migration and the marginal man”, en American fournal of Sociology, 1928, Vol. 33, № 6 .

Pedraza, Silvia, "Assimilation or Transnationalism? Conceptual Models of the Immigrant Experience”, en Ram Mahalingam (ed.), The Cultural Psychology of Immigrants, Mahwah, NJ, Lawrence Erlbaum, 2006.

Portes, Alejandro y Min Zhou, "The New Second Generation: Segmented Assimilation and Its Variants", en Annals of the American Academy of Political and Social Science, 1993, Vol. 530, № 1 . 
Ramírez Sánchez, Saúl, El sentido de transpertenencia de los mixes migrantes de Tlahuitoltepec, Oaxaca, México, Comisión Nacional para el Desarrollo de los Pueblos Indígenas, 2010.

— "Los cargos comunitarios y la transpertenencia de los migrantes mixes de Oaxaca en Estados Unidos”, en Migraciones Internacionales, 2006, Vol. 3, № 3.

Ramírez Sánchez, Saúl y J. Enrique Victoria Saavedra, "La Constitución ante el derecho internacional indígena. Tarea pendiente del Estado mexicano”, en Alegatos, 2017, Vol. 31, № 97.

Rivera-Salgado, Gaspar, "De asociaciones de oriundos a movimiento transnacional: La evolución de las asociaciones de migrantes oaxaqueños en California”, en Luis Escala Rabadán, Asociaciones inmigrantes y fronteras internacionales, México, Colegio de la Frontera Norte, Colegio de San Luis Potosí, 2016.

SChlesinger Meier, Arthur, "The significance of immigration in american history”, en The American Fournal of Sociology, 1924, Vol. 27, № 1.

Solé, C. et al., "El concepto de integración desde la sociología de las migraciones”, en Migraciones, Publicación del Instituto Universitario de Estudios sobre Migraciones, 2002, Vol. 12.

Thomas, W. I., Y Znaniecki, F., The Polish peasant in Europe and America: A classic work in immigration history, Chicago, University of Illinois Press, 1996.

Velasco Ortz, Laura y París Pombo, Dolores, "Indigenous Migration in Mexico and Central America: Interethnic Relations and Identity Transformations”, en Latin American Perspectives, 2014, Vol.41, № 3.

— "Liderazgos indígenas y política étnica transnacional en el contexto de las migraciones mexicanas a Estados Unidos”, en Luis Escala Rabadán, Asociaciones inmigrantes y fronteras internacionales, Tijuana, Colegio de la Frontera Norte, San Luis Potosí, Colegio de San Luis Potosí, 2016. 
Vertovec, Steven, "Towards post-multiculturalism? Changing communities, conditions and contexts of diversity”, en International Social Science Fournal, Vol. 61, № 199, 2010.

Walter, John C., "The Influence of African American History on U.S. History Survey Textbooks since the 1970s”, en Johnnella E. Butler (ed.), Color-Line to Borderlands. The Matrix of American Ethnic Studies, The University of Washington Press, 2001.

Wolfe, Alan, "Bening Multiculturalism", en Peter Kivisto y Georganne Rundblad (eds.), Multiculturalism in the United States: Current issues, contemporary voices, Pine Forge Press, 2000.

Yescas Angeles Trujano, Carlos, A Framework for Understanding Indigenous Migration, OIM, Organización Internacional para las Migraciones, 2008.

Zhou, Min, "Segmented Assimilation: Issues, Controversies, and Recent Research on the New Second Generation”, en The International Migration Review, 1997, Vol. 31, No. 4.

Zolberg, Aristide R., A Nation by Design: Immigration Policy in the Fashioning of America, Harvard University, 2006. 